\title{
Mechanical properties of graphene oxide-silk fibroin bionanofilms via nanoindentation experiments and finite element analysis
}

\author{
Hyeonho CHO ${ }^{1, \dagger}$, Joonho LEE $^{2,4, \dagger}$, Hyundo HWANG ${ }^{3}$, Woonbong HWANG ${ }^{3}$, Jin-Gyun KIM ${ }^{2, *}$, Sunghan KIM ${ }^{1, *}$ \\ ${ }^{1}$ School of Mechanical Engineering, Chung-Ang University, Seoul 06974, Republic of Korea \\ ${ }^{2}$ Department of Mechanical Engineering (Integrated Engineering), Kyung Hee University, Gyeonggi 17104, Republic of Korea \\ ${ }^{3}$ Department of Mechanical Engineering, POSTECH, Pohang 37673, Republic of Korea \\ ${ }^{4}$ Department of Robotics \& Mechatronics, Korea Institute of Machinery \& Materials, Daejeon 34103, Republic of Korea \\ Received: 17 September 2020 / Revised: 25 December 2020 / Accepted: 11 January 2021 \\ (C) The author(s) 2021.
}

\begin{abstract}
Understanding the mechanical properties of bionanofilms is important in terms of identifying their durability. The primary focus of this study is to examine the effect of water vapor annealed silk fibroin on the indentation modulus and hardness of graphene oxide-silk fibroin (GO-SF) bionanofilms through nanoindentation experiments and finite element analysis (FEA). The GO-SF bionanofilms were fabricated using the layer-by-layer technique. The water vapor annealing process was employed to enhance the interfacial properties between the GO and SF layers, and the mechanical properties of the GO-SF bionanofilms were found to be affected by this process. By employing water vapor annealing, the indentation modulus and hardness of the GO-SF bionanofilms can be improved. Furthermore, the FEA models of the GO-SF bionanofilms were developed to simulate the details of the mechanical behaviors of the GO-SF bionanofilms. The difference in the stress and strain distribution inside the GO-SF bionanofilms before and after annealing was analyzed. In addition, the load-displacement curves that were obtained by the developed FEA model conformed well with the results from the nanoindentation tests. In summary, this study presents the mechanism of improving the indentation modulus and hardness of the GO-SF bionanofilms through the water vapor annealing process, which is established with the FEA simulation models.
\end{abstract}

Keywords: graphene oxide; silk fibroin; layer-by-layer (LbL); nanoindentation; finite element analysis (FEA)

\section{Introduction}

Nanomaterial-based thin films are widely studied in several engineering fields owing to their excellent material properties and diverse potential applications [1-7]. Several fabrication methods have been used to develop such nanomaterials-based thin films, including solvent casting, painting, spray processing, printing, spin coating, the floating technique, pulsed laser deposition technique, and the layer-by-layer (LbL) method [8-17]. Among these thin films, graphene oxide (GO)-based thin films, which are synthesized via the LbL method, are noteworthy as they can be used to fabricate multifunctional engineering products [18-21]. GO-based functional films can be used to enhance the electrical conductivity and mechanical durability for certain engineering products [22-24]. Several types of additives have been added in fabrication processes to enhance the functional properties of GO-based thin films [25, 26]. Specifically,

$\uparrow$ Hyeonho CHO and Joonho LEE contributed equally to this work.

* Corresponding authors: Jin-Gyun KIM, E-mail: jingyun.kim@khu.ac.kr; Sunghan KIM, E-mail: sunghankim@cau.ac.kr 
bionanomaterials have been widely used to improve the engineering functionality and biocompatibility of GO-based thin films. Because biomaterials are biocompatible and biodegradable, they can replace various eco-friendly conventional engineering materials [27-29]. In addition, it is important to understand the mechanical behaviors of biomaterials that are used as vital components of durable and robust engineering applications. The key of the biomaterial-based implants is that they need to have considerable mechanical properties that allow appropriate damage tolerance $[30,31]$. Moreover, the biomaterials-based microcapsule that is impregnated with a drug component should possess a favorable hardness to enter the cell membrane. In addition, it should internalize the drug component into the target cells to create a durable drug delivery system [32, 33].

Various functional materials can be employed to build hierarchical layered thin film structures [34-38]. Among these materials, silk fibroin (SF), which is a natural polymer derived from silk cocoons, has received substantial research interest owing to its outstanding strength, favorable amphiphilic properties, and biocompatibility [39-41]. Recently, SF was combined with GO to develop functional bionanofilms that have a strong interfacial strength between the SF and GO layers [42-44]. Moreover, the water vapor annealing process was employed to improve the mechanical durability of the GO-SF bionanofilms [45]. The indentation modulus and hardness are critical factors for the protective coating films and functional carrying structures [46, 47]. Nacre-mimetic GO-SF bionanofilms can be suitable materials in their applications owing to their tailorable mechanical properties via thermal treatment and in applying several weight percentage combinations between the GO and SF [48]. Although several studies are being performed to understand the mechanical properties of the GO-SF bionanofilms, there is still a lack of fundamental knowledge about the interfacial structure of their layers that is related to their hardness and indentation modulus $[49,50]$.

The complex stress and strain fields on the materials that are generated during mechanical tests can be examined through finite element analysis (FEA) [51-53]. Several researchers have investigated the overall indentation behavior using FEA [54-60]. Tadayon et al. studied the hierarchical fiber architecture of spider fangs and tarsal claws to understand the mechanical properties that are adapted to their specific functional necessities [61]. A local hardness and reduced modulus of architecture was calculated by the nanoindentation technique, and FEA-predicted stress distribution was mapped to understand the hierarchical fiber architecture. Salinas et al. investigated a crossed lamellar microstructure of the Strombus gigas shell [62]. By using the nanoindentation technique and performing an FEA simulation, a significant correlation of the mechanical properties was observed between the orientation of the crossed lamellar micro-structure and the indenter geometry. Bhattacharya et al. compared the load-depth response of the indentation test on three specimen materials through FEA and experiments. The FEA results were observed to be reliable when compared to the experimental results. The differences between the FEA and experimental results arose from the differences in the yield stress, work hardening rate, and tip geometry [57]. In addition, Zhang et al. investigated the mechanical properties, namely the Young's modulus and hardness, of bone through indentation tests and FEA. The viscoelastic/plastic constitutive model was used in the FEA. Several testing parameters such as the maximum load, load/unload rate, and holding time were then considered [58].

In this study, the mechanical properties of the GO-SF bionanofilms, which were fabricated via the LbL technique, were investigated to understand the durability of these films in terms of the indentation modulus and hardness via nanoindentation experiments and FEA simulations (Scheme 1). To verify the effect of water vapor annealed SF on the indentation modulus and hardness of the LbL fabricated bionanofilms, nanoindentation experiments were conducted with two types of GO-SF bionanofilms, namely before and after water vapor annealing GO-SF bionanofilms. The indentation modulus and hardness of the GO-SF bionanofilms were considered in defining the tip area function between the surface of the indenter tip and that of the target sample [63]. The indentation modulus and hardness behaved differently for each of the GO-SF bionanofilms. The results indicate that densely packed hierarchical structures were formed between the GO and SF layers through water vapor 


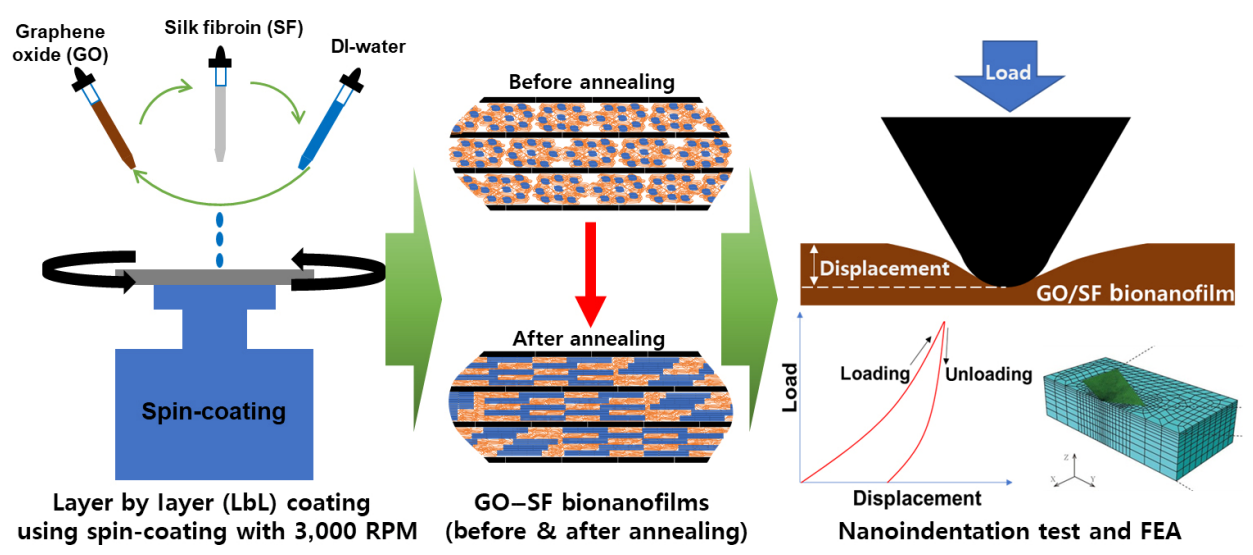

Scheme 1 Overall research outline: bionanofilm fabrication process using LbL assembly technique with graphene oxide (GO) and silk fibroin (SF), GO-SF bionanofilms before and after annealing, and nanoindentation test and FEA.

annealing, thereby enhancing the indentation properties owing to strong interfacial strength between the layers. FEA models of the LbL laminated bionanofilms have been established to simulate the mechanical behaviors of the GO-SF bionanofilms, which includes details of the stress and strain distribution under the indentation loading condition. To exemplify the effect of water vapor annealing on the FEA modeled GO-SF bionanofilms, a Prony series expansion was utilized. In addition, we demonstrated that the load-displacement curves of the GO-SF bionanofilms comply with the experimental data and the FEA simulation results.

\section{Material and methods}

\subsection{Materials}

\subsubsection{Preparation of graphene oxide (GO)}

Graphene oxide (GO) was prepared by Hummer's method [64]. In short, graphite powder $(0.8 \mathrm{~g})$ was exfoliated via sulfuric acid (18.5 mL, 95\%), sodium nitrate $(0.4 \mathrm{~g})$, and potassium permanganate $(2.4 \mathrm{~g})$ in an ice-bath, and then in a water-bath. After the exfoliated process, DI-water $(37.5 \mathrm{ml})$ was poured into the exfoliated graphite solution dropwise, and the solution was double boiled into a heated water-bath (approximately $95{ }^{\circ} \mathrm{C}$ ) for $2 \mathrm{~h}$. Afterwards, DI-water $(112.5 \mathrm{~mL})$ and hydrogen peroxide $(30 \%, 12.5 \mathrm{~mL})$ were added into the solution and stirred for $1 \mathrm{~h}$, respectively. The solution was sediment down, and the supernatant of the solution was changed with DI-water by repeating the process three times. To obtain the graphene oxide, the refined solution was filtrated using a vacuum pump and filtration paper (particle retention: $1 \mu \mathrm{m}$ ) and was dried in a $60^{\circ} \mathrm{C}$ chamber.

\subsubsection{Preparation of silk fibroin (SF)}

Silk fibroin aqueous solution was prepared from bombyx mori cocoons [65]. Briefly, silk cocoons were cleaved, degummed, and dissolved with sodium sulfate solution (0.02 M) and lithium bromide solution (9.3 M). Thereafter, the dissolved silk solution was repeatedly subjected to dialysis by applying a dialysis cassette (3,500 MW cutoff) with DI-water replacements. To purify the silk solution, centrifugation $(9,000 \mathrm{rpm}$, $10 \mathrm{~min}$ ) was performed twice while collecting supernatant after completing a process. The SF solutions were stored inside a refrigerator $\left(4^{\circ} \mathrm{C}\right)$ for a month and a half.

\subsection{Method}

\subsubsection{Fabrication of bionanofilms}

GO-SF bionanofilms were prepared with a spinassisted layer-by-layer (SA-LbL) method to assemble graphene oxide and silk fibroin stacking alternately one layer by one layer until desirable bilayers were stacked [66, 67]. Initially, an Si wafer $(20 \mathrm{~mm} \times 20 \mathrm{~mm})$ was cleaned using DI-water and sonification (15 min). Subsequently, graphene oxide $(0.3 \mathrm{wt} \%)$ and silk fibroin $(0.1 \mathrm{wt} \%)$ aqueous suspension were spun layer by layer on the cleaned Si wafer. During the SA-LbL, the bionanofilms were rinsed with DI-water to eliminate the excessively stacked material. By using the fabricated GO/SF bionanofilms, water vapor 
annealing post-treatment was conducted through a well-established procedure [41]. The bionanofilms were placed on a beaker that was filled with water in half, followed by covering the entrance of the beaker with a plastic wrap. The beaker embracing bionanofilms was in an $80^{\circ} \mathrm{C}$ chamber for $1 \mathrm{~h}$.

\subsubsection{AFM imaging for bionanofilms}

The surface characteristics of the prepared bionanofilms were studied using an atomic force microscope (AFM; NX-10, Parksystems). The morphology of the bionanofilms was observed using the contact mode with a MikroMasch cantilever conical tip (HQ:XSC11/Al BS), which has a force constant and tip radius of $0.2 \mathrm{~N} / \mathrm{m}$ and $8 \mathrm{~nm}$, respectively. The soft tapping mode was employed to scan the topographical AFM images of the bionanofilms. The scanning rate was selected as $0.5 \mathrm{~Hz}$ for all the scanned images. The topographical AFM images of the bionanofilms were scanned with $40 \mu \mathrm{m} \times 40 \mu \mathrm{m}$ selected surface areas.

\subsubsection{Nanoindentation test}

To study the mechanical properties of the GO-SF bionanofilms, the nanoindentation experiment was performed using a nanoindentation device (Nano Indenter XP, MTS Inc.). Accordingly, a diamond Berkovich tip was used. The indentation moduli and hardness of the GO-SF bionanofilms were measured using the load-displacement curve measurement function of the nanoindentation system. The indentation modulus and hardness of the GO-SF bionanofilms can be identified by applying Eqs. (1) and (2).

$$
\begin{gathered}
\frac{\mathrm{d} P}{\mathrm{~d} h}=\frac{2}{\sqrt{\pi}} M \sqrt{A} \\
H=\frac{P_{\max }}{A}
\end{gathered}
$$

where $P$ is the load, $h$ is the indentation depth, $M$ is the indentation modulus, $H$ is the hardness, $P_{\max }$ is the maximum load, and $A$ is the contact area [68]. The contact area can be defined using an area function that can be obtained by the Fused-Quartz substrate. The area function of the Berkovich tip can be expressed as

$$
\text { Area function }\left(A_{\mathrm{f}}\right)=\sum_{i=0}^{5} C_{i} h_{\mathrm{c}}^{1 / 2^{i}}
$$

where $C_{i}$ is the coefficient that is defined by the indentation experiment on the Fused-Quartz substrate, and $h_{\mathrm{c}}$ is the indentation depth that is obtained by the indentation measurements on the Fused-Quartz substrate. To define the most accurate area function, the indentation depth range on the Fused-Quartz substrate corresponds to $20 \%$ of the total thickness of the target samples (GO-SF bionanofilms). The coefficient $C_{i}$ can be determined by conducting the indentation experiment at a variable penetration position.

\subsubsection{Finite element analysis}

To validate the results of the nanoindentation experiment, FEA was conducted with ABAQUS, which is a widely used CAE software. The FEA model was designed on a nanoscale. A Berkovich tip is defined as a three-sided pyramid shape with a height of $0.6 \mu \mathrm{m}$ and a centerline to face angle of $65.3^{\circ}$. In this work, the blunt tip was defined with a radius of $15 \mathrm{~nm}$, and the indenter was then meshed with 3-D discrete rigid elements by assuming no deformation on the tip. The substrate that consists of GO and SF has a brick shape with a thickness of $500 \mathrm{~nm}$. It was modeled with a composite LbL laminate with the viscoelastic property. A Prony series expansion was considered to describe the viscoelastic behavior. The relaxation modulus $E(t)$ is defined as

$$
E(t)=E_{\infty}+\sum_{i=1}^{n} E_{i} \mathrm{e}^{\frac{-t}{\tau_{i}}}
$$

where $E_{\infty}$ is the equilibrium modulus, $E_{i}$ is the elastic modulus, and $\tau_{i}$ is the relaxation time. A pair of $E_{i}$ and $\tau_{i}$ is determined by the Prony series. Here, instantaneous modulus $E_{0}$ can be represented as

$$
E_{0}=E_{\infty}+\sum_{i=1}^{n} E_{i}
$$

Therefore, the relaxation modulus $E(t)$ can be represented as

$$
E(t)=E_{0}-\sum_{i=1}^{n} E_{i}\left(1-\mathrm{e}^{\frac{-t}{\tau_{i}}}\right)
$$

To simulate the indentation experiment, the contact between the tip and substrate should be considered. 
In this study, a frictionless condition was assumed for simplifying the tangential behavior. A symmetric model was used for the simulation to reduce the computational time.

\section{Results and discussion}

\subsection{Morphology of the GO-SF bionanofilms}

The surface morphology of the GO-SF bionanofilms before and after annealing and the thickness of the bionanofilm was examined using AFM (Fig. 1). The surface roughness of the GO-SF bionanofilm before and after annealing are $16.1 \pm 4.1 \mathrm{~nm}$ and $10.4 \pm 2.1 \mathrm{~nm}$, respectively. The values of the surface roughness indicate that the GO-SF bionanofilms that were fabricated by the SA-LbL techniques possess a smooth surface as reported in the Refs. [42, 45]. Moreover, the structural shape of the surface morphology between the two different GO-SF bionanofilms varied. Specifically, a globular type structural shape was observed through the GO-SF bionanofilm before annealing (Fig. 1(a)). Meanwhile, a more fibrillar type structural shape was discovered in the GO-SF

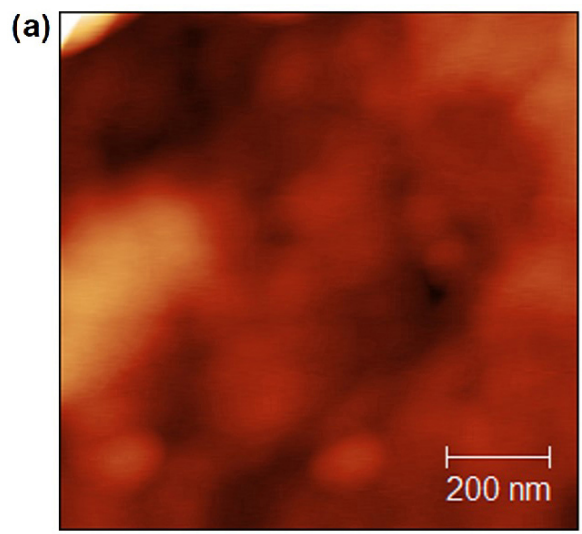

(c)

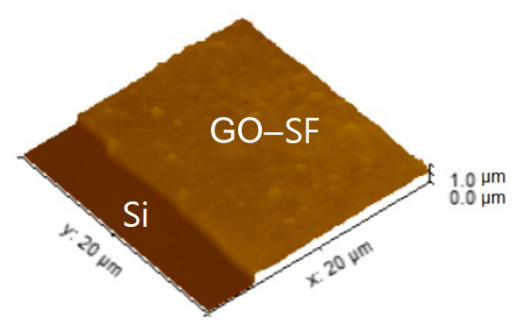

bionanofilm after annealing (Fig. 1(b)). Notably, SF molecular structures can be formed in the nanofibrillar structural type from the globular cluster-like structures after water vapor annealing [45]. The change in the structural type surface morphology of the GO-SF bionanofilms can affect the interfacial strength between the layers of the GO-SF bionanofilms, which implies that the overall indentation modulus and hardness of the GO-SF bionanofilms can be significantly changed through water vapor annealing. This will be discussed with the indentation test results in Section 3.3. The edge region of the GO-SF bionanofilms on Si substrate was scanned by performing AFM to measure the average thickness of GO-SF bionanofilms, which was approximately $519 \mathrm{~nm}$ (Figs. 1(c) and 1(d)).

\subsection{Calibration of the indentation tests}

By performing multiple indentation experiments on the Fused-Quartz substrate (indentation modulus: $69.5 \mathrm{GPa}$ ), the area function of the Berkovich tip was determined with various coefficients at each indenting depth. Multiple loads were applied to measure the mechanical properties of the Si substrate within a target indentation depth range of 5-50 nm. By using the

(b)

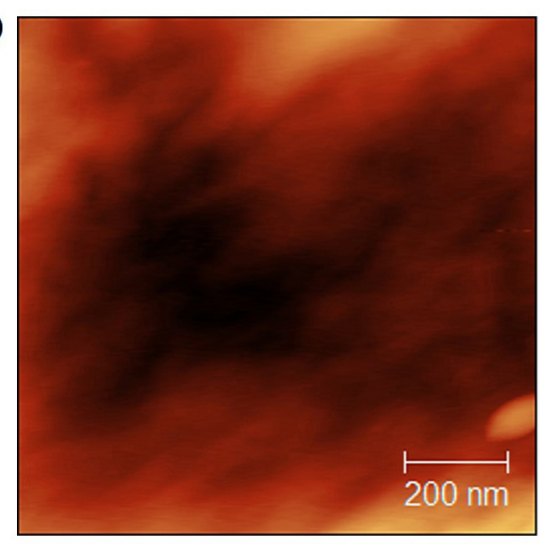

(d)

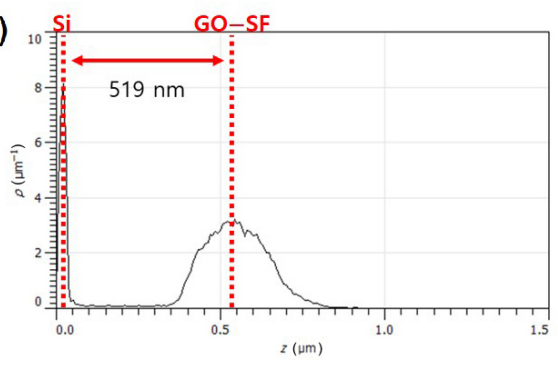

Fig. 1 Representative AFM topography images (z-scale: $150 \mathrm{~nm}$ ) of the GO-SF bionanofilms: (a) before annealing and (b) after annealing. (c) 3D topography image of the GO-SF bionanofilm on a Si substrate, and (d) the surface profile data of the GO-SF on the Si substrate to determine the thickness of the bionanofilm. 
determined area function, the indentation modulus and hardness of the $\mathrm{Si}$ substrates were measured through the indentation experiment. The statistical results of the modulus and hardness are shown in Fig. S1 in the Electronic Supplementary Material (ESM). The modulus and hardness of the Si substrate are approximately $168.9 \mathrm{GPa}$ and $12.1 \mathrm{GPa}$, respectively (Figs. S1(a) and S1(b) in the ESM). These values for the indentation modulus and hardness of both $\mathrm{Si}$ substrates correspond to the existing studies [69, 70]. According to the indentation results of the Si substrates, it can be determined that this indentation system has been calibrated.

\subsection{Nanoindentation tests of the GO/SF films}

The nanoindentation tests were performed with different types of GO-SF bionanofilms. The first group is the GO-SF bionanofilm before water vapor annealing, and the second group is the GO-SF bionanofilm after water vapor annealing. These two types of films are coated on the top surface of both Si substrates. The indentation experiments were conducted to obtain the mechanical properties, such as the indentation modulus and hardness, of those films using the loaddisplacement curves. The loading force condition was on the top surface of each bionanofilm during the nanoindentation experiments. Figure 2 presents the representative load-displacement curves before and after annealing the GO-SF bionanofilms. In both curves, no plastic deformation was observed during the nanoindentation tests. There are no substrate-effects on these results because of the small indentation depth: less than $20 \%$ of the total thickness of the bionanofilms in all cases of the indentation experiment is up to $0.75 \mathrm{mN}$ indentation for the loading condition. The viscoelastic properties of GO-SF bionanofilms can be thoroughly considered with the application of a constant loading rate region at the maximum load and at the specified unloading segment [71, 72]. Thus, two platform regions were observed throughout the load-displacement curves at the maximum loading segment and the end of the unloading segment (Fig. 2).

Figure 3 presents the results of the indentation modulus and hardness of the GO-SF bionanofilms on the Si substrates. The indentation modulus and

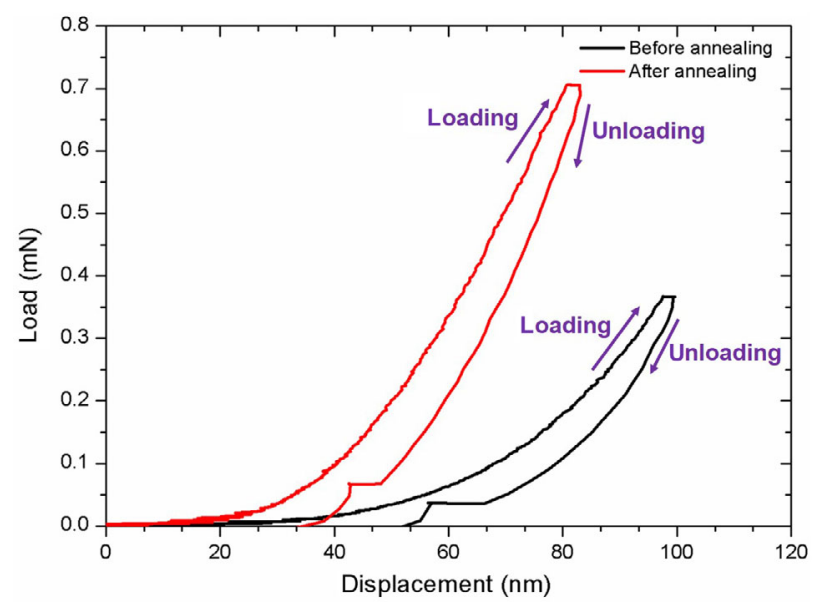

Fig. 2 Representative load-displacement curves of the GO-SF bionanofilms before and after annealing.

hardness of each sample were measured using the determined area function of the Berkovich tip. In each case, there were no considerable deviations on the indentation modulus and hardness of the bionanofilms. The GO-SF bionanofilms that were fabricated before and after annealing possessed an indentation modulus of $22.1 \pm 7.1 \mathrm{GPa}$ and $45.5 \pm 4.8 \mathrm{GPa}$, respectively. Moreover, the hardness of the GO-SF bionanofilms before and after annealing were measured to be $0.8 \pm$ $0.2 \mathrm{GPa}$ and $2.3 \pm 0.6 \mathrm{GPa}$, respectively. In addition, the average indentation modulus of the GO-SF bionanofilms after annealing was 106\% higher than that before annealing, and the hardness of the GO-SF after annealing increased with an increase of $200 \%$ than that before annealing. Therefore, the GO-SF bionanofilms before annealing have lower values for the indentation modulus and hardness rather than the GO-SF bionanofilms after annealing. The mechanical properties of the bionanofilms can be increased by conducting water vapor annealing because of the enhancement of the packing density and a more aligned domain of the silk fibroin [45]. These results indicate that water vapor annealing affects the mechanical properties of the GO-SF bionanofilms according to the observed indentation modulus and the hardness behavior. Accordingly, water vapor annealing can enhance the mechanical properties of the final GO-SF bionanofilms in terms of durability.

Higher surface area densities of SF molecular structures can be realized on GO layers, demonstrating a favorable interfacial interaction at the interface via 

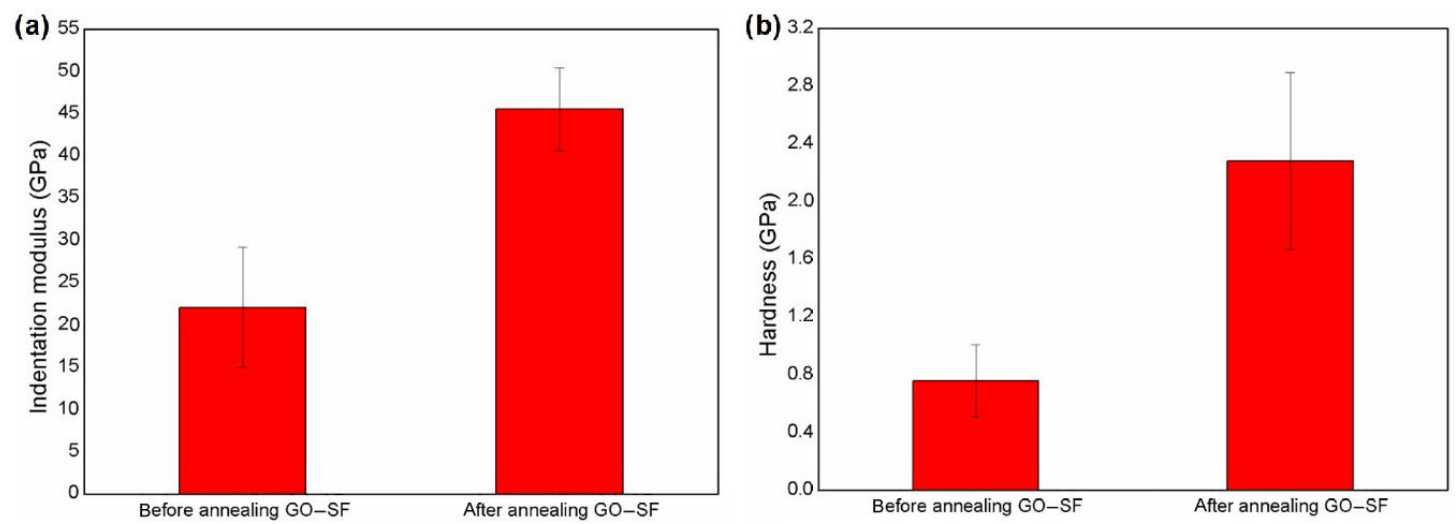

Fig. 3 Results of the indentation modulus and the hardness of the GO-SF bionanofilms before and after annealing: (a) indentation modulus and (b) hardness. Each bar is represented as the mean \pm STD.

rapid solvent evaporation after the SA-LbL process [39]. Substantial interfacial interactions can be facilitated by maximizing hydrophobic interactions, hydrogen bonding interactions, and polar-polar interactions between GO and SF owing to the densely formed SF molecules on the GO layer [39, 45]. Thus, more densely and finely formed networks of interactions between GO and SF can be developed after the water vapor annealing process (Fig. 4(a)) [39, 45]. Furthermore, the Raman spectra of the GO-SF bionanofilms indicated that peak intensity ratios of D-band $\left(I_{\mathrm{D}}\right)$ to G-band $\left(I_{\mathrm{G}}\right)$ were calculated to be 0.996 and 0.997 for the GO-SF bionanofilms before and after annealing, respectively (Fig. S2(a) in the ESM). The results demonstrated that there are similar GO-based layered structures between the GO-SF bionanofilms before and after annealing [73]. Figure S2(a) in the ESM shows that the GO-SF bionanofilms after annealing have a lower intensity at $2 \mathrm{D}$ than the intensity of these bionanofilms before annealing. One possible explanation for the decreased $2 \mathrm{D}$ band is that through water vapor annealing posttreatment, an increased content of $\beta$-sheets in SF was reconstructed, and densely packed interfacial structures were formed in the GO-SF bionanofilms [41, 45]. The thickness of the GO-SF bionanofilms before and after annealing was measured using AFM (Fig. S2(b) in the ESM), with the results yielding values of $519 \mathrm{~nm}$ and $489 \mathrm{~nm}$, respectively, which indicated that the bionanofilms were densely packed via the water vapor annealing post-treatment. As demonstrated, water vapor annealing influenced the interfacial interaction between the GO and SF layers by manipulating the structural ordering of the GO-SF bionanofilms and increasing the content of the $\beta$-sheet in the GO-SF bionanofilms [45]. The crystallinity of the SF can be changed by water vapor annealing, thereby forming a more ordered fibrillar type hierarchical structure in the GO-SF bionanofilm (Fig. 1(b)) [41]. Moreover, the $\beta$-sheet domains, which is related to the backbones of the compact-packed chains, can be increased by water vapor annealing in the GO-SF bionanofilms [41, 45]. Notably, this increases the $\beta$-sheet content in the GO-SF

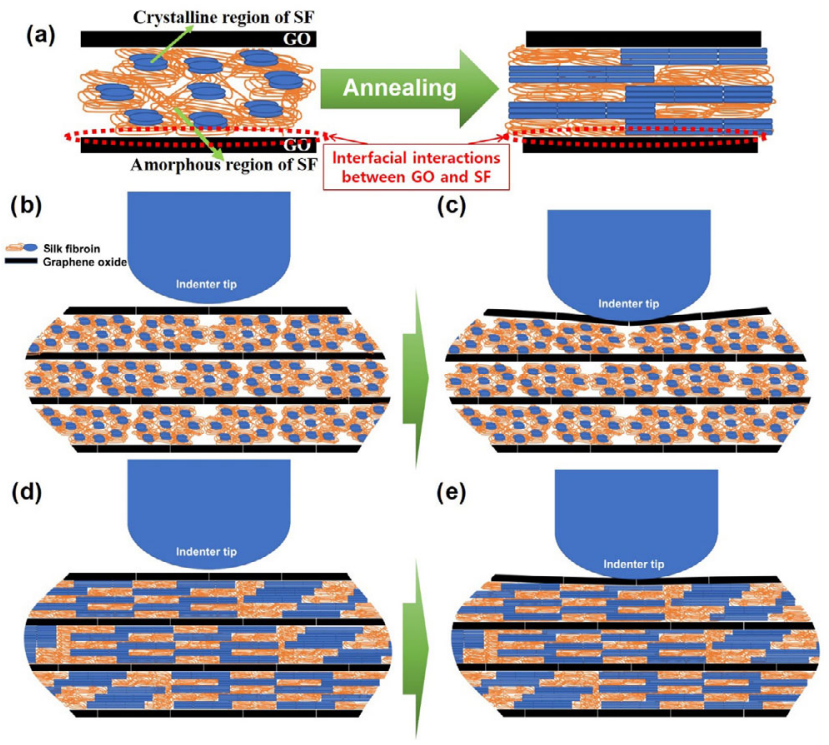

Fig. 4 (a) Basic formation model of GO-SF bionanofilms before and after annealing. Schematics of the structural changes in the GO-SF bionanofilms before annealing: (b) GO-SF bionanofilms without application of the indentation load, (c) GO-SF bionanofilms with application of the indentation load. Illustrations of the structural changes in the GO-SF bionanofilms after annealing: (d) GO-SF bionanofilms without application of the indentation load, (e) GO-SF bionanofilms with application of the indentation load. 
bionanofilms, and the highly-ordered morphological structures of the GO-SF bionanofilms can improve the mechanical performance of the GO-SF bionanofilms $[45,74,75]$.

According to the practical discussed points in the previous studies and the morphological analysis of the GO-SF bionanofilms before and after annealing in Section 3.1, structural modification of the GO-SF bionanofilms can be identified under water vapor annealing, which may affect the indentation modulus and hardness of the GO-SF bionanofilms (Figs. 4(b)4(e)). As demonstrated, the structural shape of the SF molecules, which consists of crystalline and amorphous regions, transformed from a disordered globular like nanocluster to more aligned hierarchical nanofibrils structures. In addition, the nanofibrillar-formed-SF can firmly cling to the GO layers with compact packed layers through water vapor annealing [45, 75]. Based on the strong interaction of the annealing effect between the GO and SF, the indentation behavior of the GO-SF bionanofilms before and after annealing can be determined. The densely packed, well-aligned SF nanofibrils between the GO layers can increase the mechanical strength of the GO-SF bionanofilms after annealing (Fig. 4(d)). In contrast, a globular-like nanocluster SF results in lower mechanical properties of the GO-SF bionanofilms before annealing (Fig. 4(b)). It is worth noting that the multilayered hierarchical nanofibrils SF that were obtained by water vapor annealing can result in greater mechanical properties, such as the indentation modulus and hardness, with an enhancing efficiency of the loading transfer and interfacial interactions between the GO and SF layers $[39,76]$.

\subsection{FEA simulation of the GO/SF films}

The indenter was meshed with linear triangular elements (R3D3 under ABAQUS). In this simulation, 3,831 elements were used for modeling the rigid indenter. The substrate was meshed with linear hexahedral elements (C3D8R under ABAQUS). The substrate model consisted of 14,560 elements, and the relative fine meshes were considered in the central part of the substrate to describe the contact analysis of the indenter. The substrate was designed as a solid, consisting of GO and SF layers with a thickness of
$500 \mathrm{~nm}$. For the computational efficiency, the $x$-axis cross-section of the model had a symmetrical plane. The bottom surface of the substrate was defined as the fixed boundary condition, and the concentrated force was applied to the tip of the indenter in the negative $z$-direction. We assumed that the motion of the indenter was on the $z$-axis. The specific model is demonstrated in Fig. 5.

For the FEA simulation, models were established for the GO-SF bionanofilms before and after annealing. The viscoelastic parameters of the FEA simulation were optimized to describe the experimental nanoindentation data with the substrates before and after annealing, which are listed in Table S1 in the ESM. The Prony series parameters, which are related to the damping characteristics of the viscoelasticity and time, are listed in Table S2 in the ESM.

The load-displacement curve in the nanoindentation was first investigated. The three specimens per case before and after annealing were considered in the FEA simulation. The results show that the FEA models can predict the experimental nanoindentation results for the substrates before and after annealing (Figs. 6(a) and 6(b), and Fig. S3 in the ESM). It should be noted that the substrate behavior of the viscoelastic property represented by the Prony series is significantly dependent on time [77-79]. As discussed, the experimental load-displacement curves of the nanoindentation clearly show that water vapor annealing reinforces the mechanical properties of the GO-SF bionanofilms. To describe the feature, larger parameters of the Prony

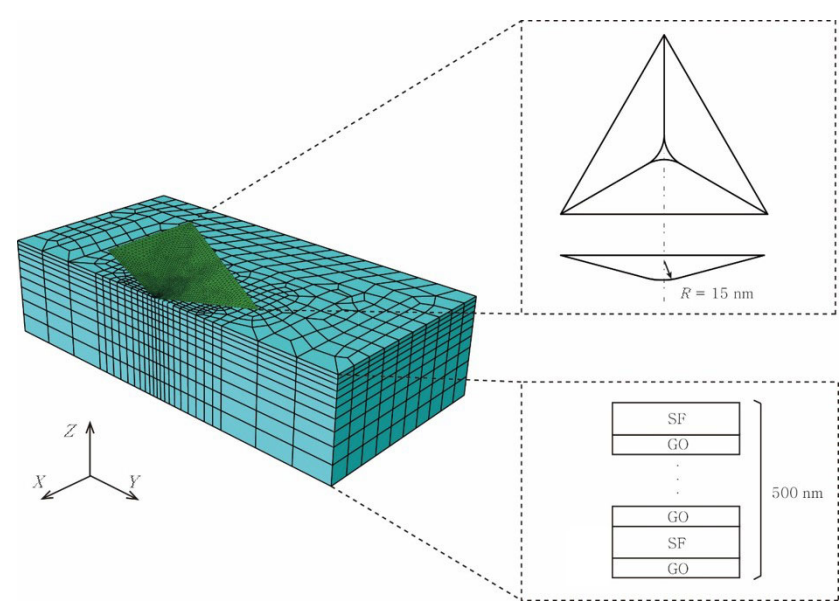

Fig. 5 FEA model of the GO-SF bionanofilm for the nanoindentation characterization. 

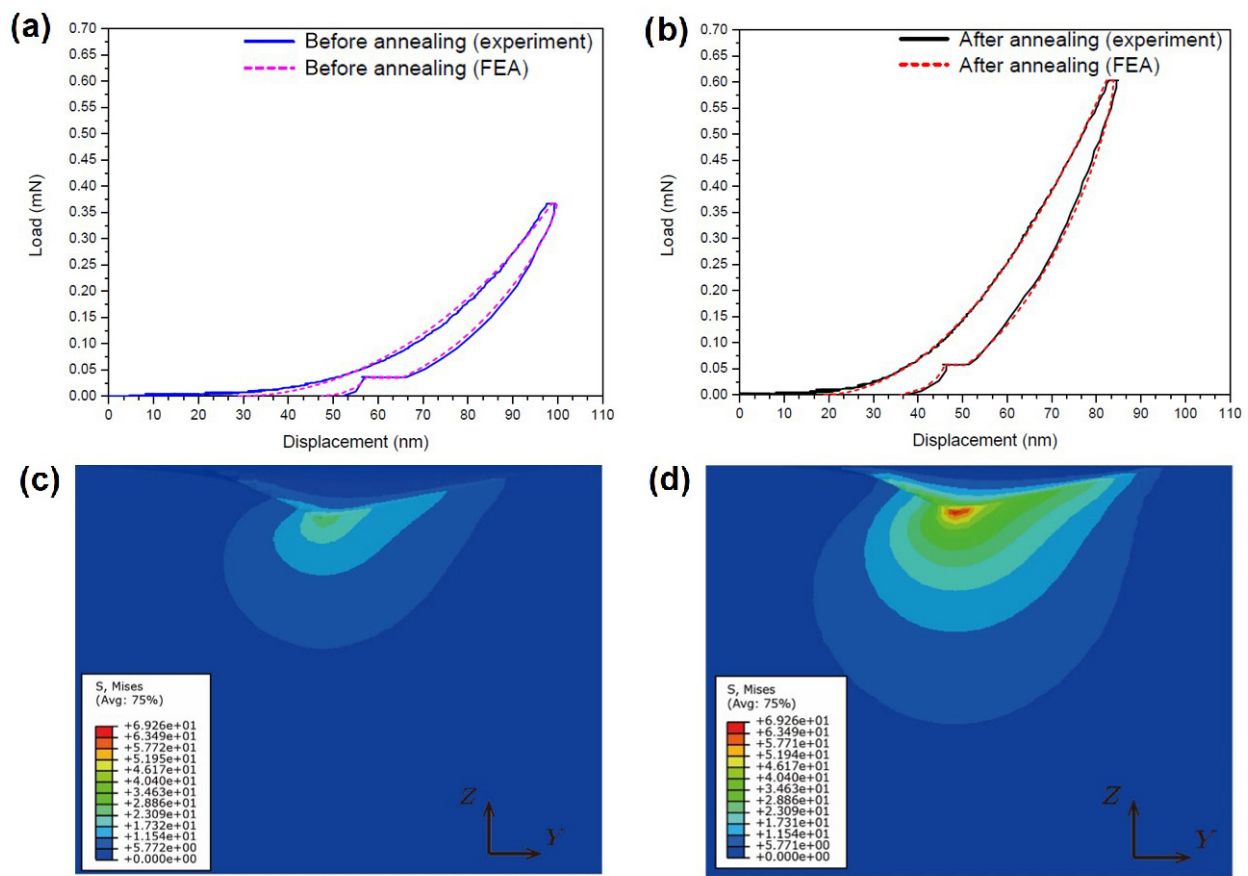

(e)

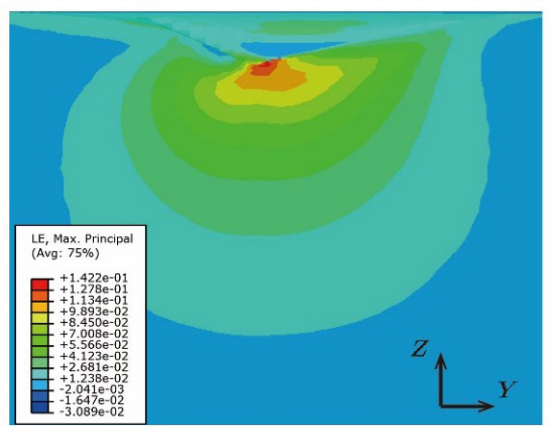

(f)

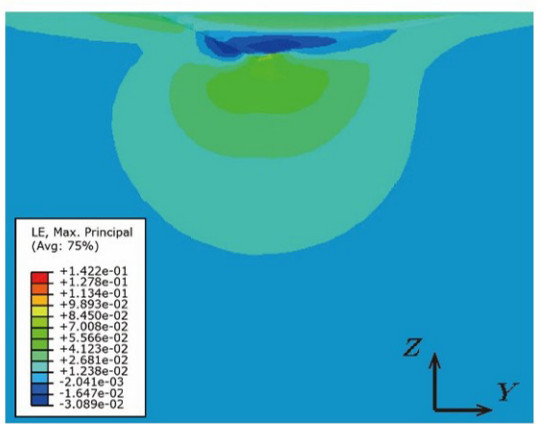

Fig. 6 Comparison between the experiment and simulation: (a) GO-SF bionanofilm before annealing, (b) GO-SF bionanofilm after annealing. Contour plots of the FEA simulation results: (c) von-Mises stress of the GO-SF bionanofilm before annealing, (d) von-Mises stress of the GO-SF bionanofilm after annealing, (e) strain of the GO-SF bionanofilm before annealing, and (f) strain of the GO-SF bionanofilm after annealing.

series for the annealing case were used instead of the ones for the before annealing case (Table S2 in the ESM). Notably, the viscoelastic creep behavior may be more significant in the GO-SF bionanofilms before annealing with loosely packed structures in terms of smaller Prony series parameters. Meanwhile, the GO-SF bionanofilms after annealing have densely packed structures with larger values for the Prony series parameters.

The FEA simulation results of the von Mises stress and the principal strain distribution indicated that complex stress and strain fields were generated during the indentation test on the GO-SF bionanofilms (Figs. 6(c)-6(f), Figs. S4 and S5 in the ESM). The maximum stress and strain were expressed at the point that contacts the tip of the indenter. The von Mises stress contour demonstrated that considerably higher von Mises stresses were observed in the GO-SF bionanofilms after annealing rather than in the GO-SF bionanofilms before annealing. However, the principal strain contour demonstrated that smaller principal strains were exhibited in the GO-SF bionanofilms after annealing rather than in the GO-SF bionanofilms before annealing. As suggested from the experimental indentation modulus and hardness results that were previously discussed, the results of the FEA analysis demonstrate that solid elastic mechanical behavior was dominant in the GO-SF bionanofilms after annealing, whereas viscoelastic behavior governed the GO-SF bionanofilms before annealing (refer the Supporting 
Information). Thus, it is possible to highlight that the highly ordered hierarchical molecular structures formed by water vapor annealing can enhance the overall mechanical behaviors of the GO-SF owing to the presence of more elastic-solid properties.

\section{Conclusions}

In this study, the mechanical properties of two different GO-SF bionanofilms were examined, including before and after water vapor annealing of GO-SF bionanofilms. The indentation modulus and hardness of the bionanofilms were measured by performing nanoindentation experiments. To ensure that the system is calibrated, the mechanical properties of the bare Si substrate was measured with the area function. The application of the water vapor annealing process on the GO-SF bionanofilms improved the indentation modulus and hardness of the bionanofilms. Highly ordered hierarchical structures in the GO-SF bionanofilms that were formed by annealing enhanced the interfacial interactions between the molecules. This causes the bionanofilms to display reinforced mechanical properties. The nanoindentation FEA simulations were performed with functionally established GO-SF bionanofilm simulation models, which includes numerical factors of the viscoelastic properties. The load-displacement curves of the GO-SF bionanofilms through the FEA simulation conformed with the experimental data. Moreover, the details of the stress and strain behaviors of the GO-SF bionanofilms under the indentation loading condition have been identified, and the simulation results revealed that improved mechanical behaviors of the bionanofilms were observed in the GO-SF bionanofilms after annealing, owing to the elastic solid dominated characteristic. The findings of this study present the detailed mechanism to improve the indentation modulus and hardness of the bionanofilms. In addition, this study offers guidance in terms of building a proper FEA model to design mechanically robust bionanofilms.

\section{Acknowledgements}

This work was supported by the National Research
Foundation of Korea (NRF) grant that was funded by the Korea Government (MSIT) (No. NRF2018R1C1B6002339).

Electronic Supplementary Material: Supplementary material is available in the online version of this article at https://doi.org/10.1007/s40544-021-0490-8.

Open Access This article is licensed under a Creative Commons Attribution 4.0 International License, which permits use, sharing, adaptation, distribution and reproduction in any medium or format, as long as you give appropriate credit to the original author(s) and the source, provide a link to the Creative Commons licence, and indicate if changes were made.

The images or other third party material in this article are included in the article's Creative Commons licence, unless indicated otherwise in a credit line to the material. If material is not included in the article's Creative Commons licence and your intended use is not permitted by statutory regulation or exceeds the permitted use, you will need to obtain permission directly from the copyright holder.

To view a copy of this licence, visit http://creativecommons.org/licenses/by/4.0/.

\section{References}

[1] Vadukumpully S, Paul J, Mahanta N, Valiyaveettil S. Flexible conductive graphene/poly (vinyl chloride) composite thin films with high mechanical strength and thermal stability. Carbon 49(1): 198-205 (2011)

[2] Luong N D, Hippi U, Korhonen J T, Soininen A J, Ruokolainen J, Johansson L S, Nam J D, Seppälä J. Enhanced mechanical and electrical properties of polyimide film by graphene sheets via in situ polymerization. Polymer 52(23): 5237-5242 (2011)

[3] Zare Y, Garmabi H. Thickness, modulus and strength of interphase in clay/polymer nanocomposites. Appl Clay Sci 105-106: 66-70 (2015)

[4] Li M T, Liu M N, Yu Y H, Li A W, Sun H B. Laserstructured graphene/reduced graphene oxide films towards bio-inspired superhydrophobic surfaces. Bull Chem Soc Jpn 92(2): 283-289 (2019)

[5] Yang Z, Guo H, Tang C Y. The upper bound of thin-film composite (TFC) polyamide membranes for desalination. $J$ Memb Sci 590: 117297 (2019)

[6] Nidamanuri N, Li Y Q, Li Q, Dong M D. Graphene and 
graphene oxide-based membranes for gas separation. Eng Sci 9: 3-16 (2020)

[7] Zhu Q S, Liu J G, Wang X, Huang Y X, Ren Y, Song W Q, $\mathrm{Mu} \mathrm{C} \mathrm{Z,} \mathrm{Liu} \mathrm{X} \mathrm{H,} \mathrm{Wei} \mathrm{F} \mathrm{C,} \mathrm{Liu} \mathrm{C} \mathrm{T.} \mathrm{Polypyrrole}$ functionalized graphene oxide accelerated zinc phosphate coating under low-temperature. ES Mater Manuf 9: 48-54 (2020)

[8] Tu J Y, Li H R, Zhang J J, Hu D, Cai Z Q, Yin X Z, Dong L J, Huang L P, Xiong C X, Jiang M. Latent heat and thermal conductivity enhancements in polyethylene glycol/polyethylene glycol-grafted graphene oxide composites. Adv Compos Hybrid Mater 2(3): 471-480 (2019)

[9] Siemann U. Solvent cast technology-A versatile tool for thin film production. In Scattering Methods and the Properties of Polymer Materials. Stribeck N, Smarsly B, Eds. Berlin, Heidelberg: Springer, 2005: 1-14.

[10] Kim S S, Na S I, Jo J, Tae G, Kim D Y. Efficient polymer solar cells fabricated by simple brush painting. Adv Mater 19(24): 4410-4415 (2007)

[11] Vak D, Kim S S, Jo J, Oh S H, Na S I, Kim J, Kim D Y. Fabrication of organic bulk heterojunction solar cells by a spray deposition method for low-cost power generation. Appl Phys Lett 91(8): 081102 (2007)

[12] Aernouts T, Aleksandrov T, Girotto C, Genoe J, Poortmans J. Polymer based organic solar cells using ink-jet printed active layers. Appl Phys Lett 92(3): 033306 (2008)

[13] Hall D B, Underhill P, Torkelson J M. Spin coating of thin and ultrathin polymer films. Polym Eng Sci 38(12): 2039-2045 (1998)

[14] Huang J S, Juszkiewicz M, De Jeu W H, Cerda E, Emrick T, Menon N, Russell T P. Capillary wrinkling of floating thin polymer films. Science 317(5838): 650-653 (2007)

[15] Eason R. Pulsed Laser Deposition of Thin Films: Applicationsled Growth of Functional Materials. Hoboken (USA): John Wiley \& Sons, 2007.

[16] Jang W S, Rawson I, Grunlan J C. Layer-by-layer assembly of thin film oxygen barrier. Thin Solid Films 516(15): 4819-4825 (2008)

[17] Liu C Q, Chen M, Yu W, He Y. Recent advance on graphene in heat transfer enhancement of composites. ES Energy Environ 2: 31-42 (2018)

[18] Chen J T, Fu Y J, An Q F, Lo S C, Huang S H, Hung W S, $\mathrm{Hu} \mathrm{C} \mathrm{C}$, Lee K R, Lai J Y. Tuning nanostructure of graphene oxide/polyelectrolyte LbL assemblies by controlling $\mathrm{pH}$ of GO suspension to fabricate transparent and super gas barrier films. Nanoscale 5(19): 9081-9088 (2013)

[19] Xiong R, Hu K S, Zhang S D, Lu C H, Tsukruk V V. Ultrastrong freestanding graphene oxide nanomembranes with surface-enhanced Raman scattering functionality by solvent-assisted single-component layer-by-layer assembly. ACS Nano 10(7): 6702-6715 (2016)

[20] Zou J L, Kim F. Diffusion driven layer-by-layer assembly of graphene oxide nanosheets into porous three-dimensional macrostructures. Nat Commun 5(1): 5254 (2014)

[21] Ariga K, Ahn E, Park M, Kim B S. Layer-by-layer assembly: Recent progress from layered assemblies to layered nanoarchitectonics. Chem-An Asian J 14(15): 2553-2566 (2019)

[22] Carosio F, Laufer G, Alongi J, Camino G, Grunlan J C. Layer-by-layer assembly of silica-based flame retardant thin film on PET fabric. Polym Degrad Stab 96(5): 745-750 (2011)

[23] Laufer G, Carosio F, Martinez R, Camino G, Grunlan J C. Growth and fire resistance of colloidal silica-polyelectrolyte thin film assemblies. J Colloid Interface Sci 356(1): 69-77 (2011)

[24] Guin T, Krecker M, Milhorn A, Hagen D A, Stevens B, Grunlan J C. Exceptional Flame resistance and gas barrier with thick multilayer nanobrick wall thin films. Adv Mater Interfaces 2(11): 1500214 (2015)

[25] Han S T, Zhou Y, Wang C D, He L F, Zhang W J, Roy V A L. Layer-by-layer-assembled reduced graphene oxide/gold nanoparticle hybrid double-floating-gate structure for lowvoltage flexible flash memory. Adv Mater 25(6): 872-877 (2013)

[26] Gao Z, Yang W L, Wang J, Yan H J, Yao Y, Ma J, Wang B, Zhang M L, Liu L H. Electrochemical synthesis of layerby-layer reduced graphene oxide sheets/polyaniline nanofibers composite and its electrochemical performance. Electrochim Acta 91: 185-194 (2013).

[27] Shao Z Z, Vollrath F. Surprising strength of silkworm silk. Nature 418(6899): 741 (2002)

[28] Xiong R, Kim H S, Zhang S D, Kim S, Korolovych V F, Ma R L, Yingling Y G, Lu C H, Tsukruk V V. Templateguided assembly of silk fibroin on cellulose nanofibers for robust nanostructures with ultrafast water transport. ACS Nano 11(12): 12008-12019 (2017)

[29] Zou D, Luo X, Han C Z, Li J A, Yang P, Li Q, Huang N. Preparation of a biomimetic ECM surface on cardiovascular biomaterials via a novel layer-by-layer decellularization for better biocompatibility. Mater Sci Eng: C 96: 509-521 (2019)

[30] Han M D, Wang H L, Yang Y Y, Liang C M, Bai W B, Yan Z, Li H B, Xue Y G, Wang X L, Akar B, et al. Three-dimensional piezoelectric polymer microsystems for vibrational energy harvesting, robotic interfaces and biomedical implants. Nat Electron 2(1): 26-35 (2019)

[31] Attar H, Bermingham M J, Ehtemam-Haghighi S, DehghanManshadi A, Kent D, Dargusch M S. Evaluation of the mechanical and wear properties of titanium produced by three 
different additive manufacturing methods for biomedical application. Mater Sci Eng: A 760: 339-345 (2019)

[32] Li Y, Zhang X R, Cao D P. Nanoparticle hardness controls the internalization pathway for drug delivery. Nanoscale 7(6): 2758-2769 (2015)

[33] Ye C H, Malak S T, Hu K S, Wu W B, Tsukruk V V. Cellulose nanocrystal microcapsules as tunable cages for nano-and microparticles. ACS Nano 9(11): 10887-10895 (2015)

[34] Madhusudhana A M, Mohana K N S, Hegde M B, Nayak S R, Rajitha K, Swamy N K. Functionalized graphene oxide-epoxy phenolic novolac nanocomposite: An efficient anticorrosion coating on mild steel in saline medium. $A d v$ Compos Hybrid Mater 3(2): 141-155 (2020)

[35] Shahc N, Aslam S, Ul-Islam M, Arain M B, Rehan T, Naeem M, Ullah M W, Yang G. Fabrication of thermally stable graphite-based poly (acrylonitrile-co-acrylic acid) composite with impressive antimicrobial properties. Eng Sci 6: 77-85 (2019)

[36] Boni B O O, Lamboni L, Bakadia B M, Hussein S A, Yang G. Combining silk sericin and surface micropatterns in bacterial cellulose dressings to control fibrosis and enhance wound healing. Eng Sci 10: 68-77 (2020)

[37] Feng P F, Ma L C, Wu G S, Li X R, Zhao M, Shi L L, Wang M Y, Wang X J, Song G J. Establishment of multistage gradient modulus intermediate layer between fiber and matrix via designing double "rigid-flexible" structure to improve interfacial and mechanical properties of carbon fiber/resin composites. Compos Sci Technol 200: 108336 (2020)

[38] Shi L L, Song G J, Li P Y, Li X R, Pan D, Huang Y D, Ma L C, Guo Z H. Enhancing interfacial performance of epoxy resin composites via in-situ nucleophilic addition polymerization modification of carbon fibers with hyperbranched polyimidazole. Compos Sci Technol 201: 108522 (2021)

[39] Hu K S, Gupta M K, Kulkarni D D, Tsukruk V V. Ultrarobust graphene oxide-silk fibroin nanocomposite membranes. Adv Mater 25(16): 2301-2307 (2013)

[40] Geryak R, Quigley E, Kim S, Korolovych V F, Calabrese R, Kaplan D L, Tsukruk V V. Tunable interfacial properties in silk ionomer microcapsules with tailored multilayer interactions. Macromol Biosci 19(3): 1800176 (2019)

[41] Hu X, Shmelev K, Sun L, Gil E S, Park S H, Cebe P, Kaplan D L. Regulation of silk material structure by temperaturecontrolled water vapor annealing. Biomacromolecules 12(5): 1686-1696 (2011)

[42] Hu K S, Kulkarni D D, Choi I, Tsukruk V V. Graphenepolymer nanocomposites for structural and functional applications. Prog Polym Sci 39(11): 1934-1972 (2014)

[43] Cheng Y, Koh L D, Li D C, Ji B H, Zhang Y Y, Yeo J,
Guan G J, Han M Y, Zhang Y W. Peptide-graphene interactions enhance the mechanical properties of silk fibroin. ACS Appl Mater Interfaces 7(39): 21787-21796 (2015)

[44] Xie W T, Tadepalli S, Park S H, Kazemi-Moridani A, Jiang Q S, Singamaneni S, Lee J H. Extreme mechanical behavior of nacre-mimetic graphene-oxide and silk nanocomposites. Nano Lett 18(2): 987-993 (2018)

[45] Wang Y X, Ma R L, Hu K S, Kim S, Fang G Q, Shao Z Z, Tsukruk V V. Dramatic enhancement of graphene oxide/silk nanocomposite membranes: Increasing toughness, strength, and young's modulus via annealing of interfacial structures. ACS Appl Mater Interfaces 8(37): 24962-24973 (2016)

[46] Masanta M, Shariff S M, Choudhury A R. Evaluation of modulus of elasticity, nano-hardness and fracture toughness of $\mathrm{TiB}_{2}-\mathrm{TiC}-\mathrm{Al}_{2} \mathrm{O}_{3}$ composite coating developed by SHS and laser cladding. Mater Sci Eng: A 528(16-17): 5327-5335 (2011)

[47] Kim S, Polycarpou A A, Liang H. Morphology and electric potential-induced mechanical behavior of metallic porous nanostructures. Friction 8(3): 604-612 (2020)

[48] Tadepalli S, Hamper H, Park S H, Cao S S, Naik R R, Singamaneni S. Adsorption behavior of silk fibroin on amphiphilic graphene oxide. ACS Biomater Sci Eng 2(7): 1084-1092 (2016)

[49] Li M, Xiong P, Mo M S, Cheng Y, Zheng Y F. Electrophoretic-deposited novel ternary silk fibroin/graphene oxide/hydroxyapatite nanocomposite coatings on titanium substrate for orthopedic applications. Front Mater Sci 10(3): 270-280 (2016)

[50] Wang F, Aravind S S J, Wu H, Forys J, Venkataraman V, Ramanujachary $\mathrm{K}, \mathrm{Hu} \mathrm{X}$. Tunable green graphene-silk biomaterials: Mechanism of protein-based nanocomposites. Mater Sci Eng: C 79: 728-739 (2017)

[51] Cho H, Lee J, Hong S, Kim S. Bulletproof performance of composite plate fabricated using shear thickening fluid and natural fiber paper. Appl Sci 10(1): 88 (2020)

[52] Mohammadpour E, Awang M, Kakooei S, Akil H M. Modeling the tensile stress-strain response of carbon nanotube/ polypropylene nanocomposites using nonlinear representative volume element. Mater Des 58: 36-42 (2014)

[53] Meng Y G, Xu J, Jin Z M, Prakash B, Hu Y Z. A review of recent advances in tribology. Friction 8(2): 221-300 (2020)

[54] Shirazi H A, Mirmohammadi S A, Shaali M, Asnafi A, Ayatollahi M R. A constitutive material model for a commercial PMMA bone cement using a combination of nano-indentation test and finite element analysis. Polym Test 59: 328-335 (2017)

[55] Bruet B J F, Qi H J, Boyce M C, Panas R, Tai K, Frick L, Ortiz C. Nanoscale morphology and indentation of individual nacre tablets from the gastropod mollusc Trochus niloticus. J Mater Res 20(9): 2400-2419 (2005) 
[56] Katti D R, Katti K S, Sopp J M, Sarikaya M. 3D finite element modeling of mechanical response in nacre-based hybrid nanocomposites. Comput Theor Polym Sci 11(5): 397-404 (2001)

[57] Bhattacharya A K, Nix W D. Finite element simulation of indentation experiments. Int J Solids Struct 24(9): 881-891 (1988)

[58] Zhang J Z, Niebur G L, Ovaert T C. Mechanical property determination of bone through nano- and micro-indentation testing and finite element simulation. J Biomech 41(2): 267-275 (2008)

[59] Bolshakov A, Oliver W C, Pharr G M. Influences of stress on the measurement of mechanical properties using nanoindentation: Part II. Finite element simulations. J Mater Res 11(3): 760-768 (1996)

[60] Bhattacharya A K, Nix W D. Analysis of elastic and plastic deformation associated with indentation testing of thin films on substrates. Int J Solids Struct 24(12): 1287-1298 (1988)

[61] Tadayon M, Younes-Metzler O, Shelef Y, Zaslansky P, Rechels A, Berner A, Zolotoyabko E, Barth F G, Fratzl P, Bar-On B, et al. Adaptations for wear resistance and damage resilience: Micromechanics of Spider Cuticular "Tools". Adv Funct Mater 30(32): 2000400 (2020)

[62] Salinas C L, de Obaldia E E, Jeong C, Hernandez J, Zavattieri $\mathrm{P}$, Kisailus D. Enhanced toughening of the crossed lamellar structure revealed by nanoindentation. J Mech Behav Biomed Mater 76: 58-68 (2017)

[63] Mc Elhaney K W, Vlassak J J, Nix W D. Determination of indenter tip geometry and indentation contact area for depth-sensing indentation experiments. J Mater Res 13(5): 1300-1306 (1998)

[64] Hummers Jr W S, Offeman R E. Preparation of graphitic oxide. J Am Chem Soc 80(6): 1339 (1958)

[65] Rockwood D N, Preda R C, Yücel T, Wang X Q, Lovett M L, Kaplan D L. Materials fabrication from Bombyx mori silk fibroin. Nat Protoc 6(10): 1612-1631 (2011)

[66] Kim S, Geryak R D, Zhang S D, Ma R L, Calabrese R, Kaplan D L, Tsukruk V V. Interfacial shear strength and adhesive behavior of silk ionomer surfaces. Biomacromolecules 18(9): 2876-2886 (2017)

[67] Kim S, Xiong R, Tsukruk V V. Probing flexural properties of cellulose nanocrystal-graphene nanomembranes with

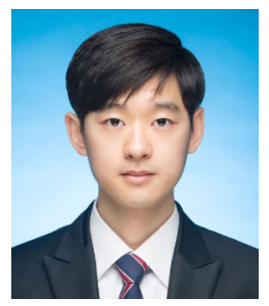

Hyeonho CHO. He received his B.S. degree in School of Mechanical Engineering from Chung-Ang University in 2019. He is currently a Ph.D. student in Department of force spectroscopy and bulging test. Langmuir 32(21): 5383-5393 (2016)

[68] Oliver W C, Pharr G M. An improved technique for determining hardness and elastic modulus using load and displacement sensing indentation experiments. $J$ Mater Res 7(6): 1564-1583 (1992)

[69] Pergande S R, Polycarpou A A, Conry T F. Nanomechanical properties of aluminum 390-T6 rough surfaces undergoing tribological testing. J Tribol 126(3): 573-582 (2004).

[70] Xu D, Liechti K M. Bulge testing transparent thin films with moiré deflectometry. Exp Mech 50(2): 217-225 (2010)

[71] Hardiman M, Vaughan T J, McCarthy C T. The effects of pile-up, viscoelasticity and hydrostatic stress on polymer matrix nanoindentation. Polym Test 52: 157-166 (2016)

[72] Yang S, Zhang Y W, Zeng K Y. Analysis of nanoindentation creep for polymeric materials. J Appl Phys 95: 3655-3666 (2004)

[73] Wang Q, Wang C Y, Zhang M C, Jian M Q, Zhang Y Y. Feeding single-walled carbon nanotubes or graphene to silkworms for reinforced silk fibers. Nano Lett 16: 6695-6700 (2016)

[74] Barthelat F, Yin Z, Buehler M J. Structure and mechanics of interfaces in biological materials. Nat Rev Mater 1(4): 16007 (2016).

[75] Kulkarni D D, Kim S, Chyasnavichyus M, Hu K S, Fedorov A G, Tsukruk V V. Chemical reduction of individual graphene oxide sheets as revealed by electrostatic force microscopy. $J$ Am Chem Soc 136(18): 6546-6549 (2014)

[76] Xu J, Zhao X L, Munroe P, Xie Z H. Synergistic toughening of hard, nacre-mimetic $\mathrm{MoSi}_{2}$ coatings by self-assembled hierarchical structure. Sci Rep 4(1): 4239 (2014).

[77] Park S W, Kim Y R. Fitting Prony-series viscoelastic models with power-law presmoothing. J Mater Civil Eng 13(1): 26-32 (2001)

[78] Park S W, Schapery R A. Methods of interconversion between linear viscoelastic material functions. Part I-A numerical method based on Prony series. Int J Solids Struct 36(11): 1653-1675 (1999)

[79] Zhang J S, Ru J, Chen H L, Li D C, Lu J. Viscoelastic creep and relaxation of dielectric elastomers characterized by a Kelvin-Voigt-Maxwell model. Appl Phys Lett 110(4): 044104 (2017)

Mechanical Engineering at Chung-Ang University. His research interests lie in evaluating mechanical properties of functional nanocomposites and fabricating micro/nano films for electromechanical applications. 


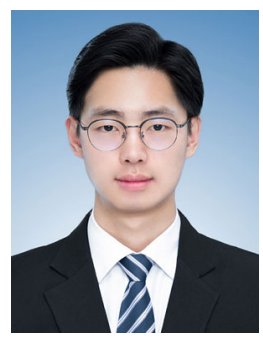

Joonho LEE. He received his B.S. and M.E. degrees in Department of Mechanical Engineering from Kyung Hee University in 2019 and

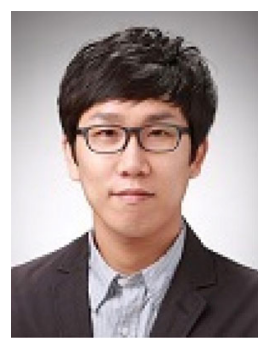

Jin-Gyun KIM. He received his B.S. and M.E. degrees in Civil Engineering from Korea University in 2008 and 2010, respectively, and his Ph.D. degree in ocean systems engineering from Korea Advanced Institute of Science and Technology (KAIST) in

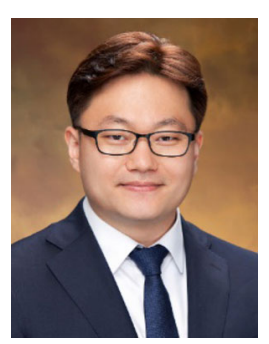

Sunghan KIM. He is an assistant professor of School of Mechanical Engineering at Chung-Ang University. He received his Ph.D. degree in J. Mike Walker '66 Department of Mechanical Engineering at Texas A\&M University in 2015. He
2020, respectively. He is currently a researcher in Korea Institute of Machinery and Materials (KIMM). His research interest is based on kinematics and dynamic contact simulation.

2014. He worked as a senior researcher in Korea Institute of Machinery and Materials (KIMM) from 2014 to 2017. He is currently an assistant professor of Kyung Hee University of Mechanical Engineering. His research area is computational dynamics, vibration, and multiphysics modeling and simulation.

worked as a postdoctoral fellow in School of Materials Science and Engineering at Georgia Institute of Technology from 2015 to 2017. His research interests lie in establishing essential design factors to optimize the tribological and mechanical properties of sustainable functional nanocomposites for biological, electrochemical, and mechanical applications. 